\title{
Multiple mononeuritis and radiculitis with erythema, pain, elevated CSF protein and pleocytosis (Bannwarth's syndrome)
}

\author{
CH WULFF, K HANSEN, P STRANGE, W TROJABORG \\ From the Laboratory of Clinical Neurophysiology and the Department of Neurology, Rigshospitalet, \\ University Hospital of Copenhagen, Denmark
}

SUMMARY Four patients with Bannwarth's syndrome were examined. One to three weeks after the appearance of a large erythematous skin lesion they developed pain of variable localisation. Four days to four weeks later uni- or bilateral facial palsies and other nerve lesions developed. CSF showed elevated.protein and mononuclear pleocytosis. There was a defect of the bloodbrain barrier and increased intrathecal production of IgG. Facial nerve latencies were increased 4 to 7 times in three cases and normal in one case examined 15 months after onset. Conduction velocity along other nerves was normal apart from slight slowing in one diabetic patient. Recovery was incomplete in three patients 8 to 15 months after onset of disease and complete in one patient after 15 months.

Bannwarth's syndrome is a lymphocytic meningoradiculitis characterised by pain, sensory and motor disturbances in the distribution of peripheral nerves, especially the facial. ${ }^{1-5}$ Symptoms are often preceded by an erythema sometimes related to a tick bite. $^{4-7}$ In this report we describe four cases of Bannwarth's syndrome including the results of cerebrospinal fluid (CSF) examination and electrophysiological studies.

\section{Case reports}

Case 1 A 53-year-old female was admitted to hospital with bilateral facial palsies and double vision. She had previously been healthy apart from mild psoriasis. Five weeks before admission she developed over a few days a $10 \mathrm{~cm}$ erythematous patch under the right breast possibly following an insect bite. Fourteen days later she complained of a severe burning pain located to the lower lateral aspect of the right chest wall, spreading to the back especially between the shoulder blades and up to the neck. The intensity of the pain fluctuated and was worse during the night. After a further two weeks she developed a left-sided facial palsy, three days later double vision and then a right-sided facial palsy. She felt very tired and had a headache. Four

Addresss for reprint requests: W Trojaborg, Laboratory of Clinical Neurophysiology, Rigshospitalet, Blegdamsvej 9, DK 2100 Copenhagen, Denmark.

Received 4 September 1982 and in revised form 4 January 1983 Accepted 17 January 1983 weeks later she complained of tingling paraesthesias in both hands. On examination at the time of admission the erythema under the right breast had disappeared, but a "butterfly" erythema was present over the face. There was no neck stiffness. There were bilateral infranuclear facial palsies, greater on the left and a right-sided abducens nerve palsy. All tendon reflexes were normal and the plantar responses were flexor. Symptomatically the patient improved. The sensory symptoms in the limbs resolved in 3 weeks and the diplopia in $2 \frac{1}{2}$ months. All the tendon reflexes apart from the knee jerks were unobtainable after 1 month. The clinical and otoneurological findings of this and the following patients are summarised in tables 1 and 2. A large number of tests including ESR, white cell count, blood glucose, serum IgG, IgE, IgA, anti-DNA, ANA, RAT, Rose-Waaler, WR, herpes zoster antibody titres and RSSE (Russian spring-summer encephalitis) antibody titres were normal. The IgM level was $2.48 \mathrm{~g} / 1(\mathrm{~N}=0.23-$ 1.67). Examination for enterovirus in the stool was negative. A CT scan of the brain was normal. Two EEGs were unremarkable. The CSF findings in this and the other three patients are shown in table 3 . Eleven weeks later the abnormalities were still present but less marked (fig). Electromyographic examination of the orbicularis oris, triangularis and frontalis muscles was carried out 5 weeks after the onset of the left facial palsy. Profuse fibrillation potentials without any voluntary activity were found in the orbicularis oris and triangularis muscles on the left. In the left frontalis muscle there was discrete activity of low amplitude $(150 \mu \mathrm{V})$ on volition and only a few fibrillation potentials. The EMG of the corresponding right-sided muscles showed no abnormalities. The latencies to the left orbicularis oris and triangularis muscles were markedly 
Table 1 Clinical findings in four cases of Bannwarth's syndrome

\begin{tabular}{|c|c|c|c|c|}
\hline & Case 1 & Case 2 & Case 3 & Case 4 \\
\hline $\begin{array}{l}\text { Age (years) } \\
\text { Sex } \\
\text { Pain }\end{array}$ & $\begin{array}{c}53 \\
\text { female } \\
+(2)\end{array}$ & $\begin{array}{r}58 \\
\text { male } \\
+(3)\end{array}$ & $\begin{array}{c}41 \\
\text { male } \\
+(1)\end{array}$ & $\begin{array}{c}64 \\
\text { female } \\
+(2)\end{array}$ \\
\hline $\begin{array}{l}\text { Cranial nerves } \\
\text { Facial palsy, unilateral } \\
\text { Second facial palsy } \\
\text { Other cranial nerves affected }\end{array}$ & $\begin{array}{l}+(4) \\
+(5) \\
\text { VI }\end{array}$ & $\begin{array}{l}+(5) \\
+(7) \\
+\end{array}$ & $+\frac{(5)}{-}$ & $\begin{array}{l}+(21 / 2) \\
\text { III } \\
\text { L\&R VI } \\
\text { IX }\end{array}$ \\
\hline $\begin{array}{l}\text { Peripheral nerves } \\
\text { Motor } \\
\text { Sensory }\end{array}$ & $\overline{+}$ & $\begin{array}{l}+ \\
+\end{array}$ & $\begin{array}{l}+ \\
+\end{array}$ & $\begin{array}{l}+ \\
+\end{array}$ \\
\hline
\end{tabular}

Figures in parentheses denote number of weeks since onset of erythema

Table 2 Otoneurological findings in three patients with Bannwarth's syndrome

\begin{tabular}{llll}
\hline & Case 1 & Case 2 & Case 3 \\
\hline Nasolacrimal reflex & $+/+a$ & $+/+$ & $+/+$ \\
Stapedius reflex & $+/+$ & $0 /+$ & $0 /+$ \\
Taste & $+/-$ & $0 /+$ & ne \\
\hline
\end{tabular}

$\mathrm{a}=$ right/left, $+=$ present, $0=$ absent,

$-=$ diminished, ne $=$ not examined

increased and the muscle action potentials were of low amplitude (table 4). The left median nerve was normal electrophysiologically.

Case 2 A 58-year-old male was admitted to hospital because of a right-sided facial palsy. Six weeks previously he had noticed a $10-15 \mathrm{~cm}$ round, slightly painful, red skin lesion around his right nipple. Three weeks later he suffered severe burning sensations between the shoulder blades and in the back of his neck. He also complained of painful dysaesthesia to light touch over the posterior aspect of both upper arms (T2 dermatomes) and the anterior part of the chest. This area extended over the next week to involve most of the body. Sometimes he also noticed patches of hyposensitivity. He felt generally ill and tired but had no fever. Three days before admission he developed a total right-sided facial palsy, and 12 days later an incomplete left-sided facial palsy. The painful paraesthesias, skin lesion, fatigue and left-sided facial palsy disappeared within three months. Remission of the rightsided facial palsy began after six months, but was incom-

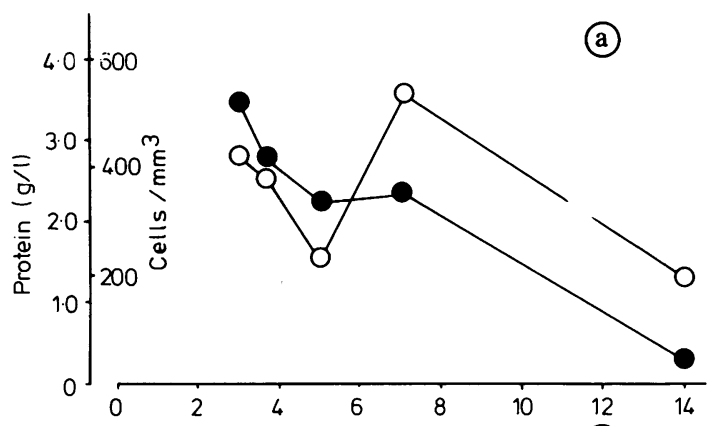

(b)

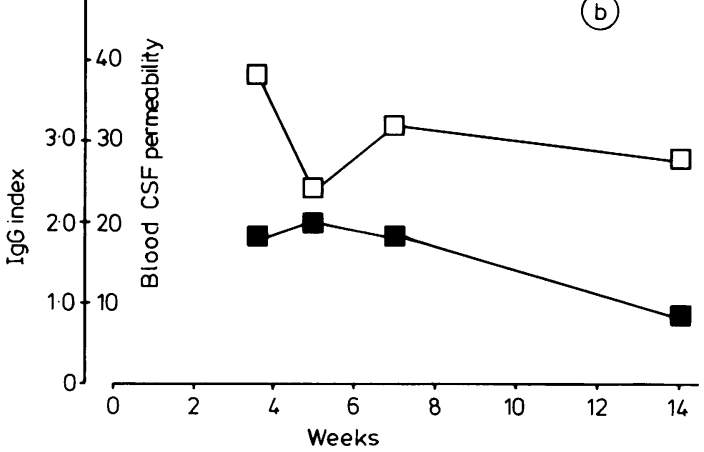

Fig CSF changes in a case of Bannwarth's syndrome (case 1). Ordinate: (a) $\bigcirc-\bigcirc$ protein $\mathrm{g} / \mathrm{l}, \mathrm{O}-\mathrm{cells} / \mathrm{mm}^{3} ; \mathrm{C}^{(b)}$ $\square$ IgG index (normal <0.63); $\square-\square$ blood CSF permeability (normal $\left(2 \cdot 6-13.9 \times 10^{3}\right)$. Abscissa: time since onset of pain (weeks).

Table 3 CSF findings in four patients with Bannwarth's syndrome (first examination)

\begin{tabular}{|c|c|c|c|c|}
\hline & Case 1 & Case 2 & Case 3 & Case 4 \\
\hline $\begin{array}{l}\text { Weeks after onset of pain } \\
\text { Days after onset of neurological symptoms } \\
\text { Protein } g / 1 \\
\text { Leucocytes per } \mathrm{mm}^{3} \\
\text { Mononuclear }(\%) \\
\text { IgG index }(<0.63)^{*} \\
\text { Albumin permeability }\left(2.6 \times 10^{-3}-13.9 \times 10^{-3}\right) \dagger\end{array}$ & $\begin{array}{l}3 \\
10 \\
2 \cdot 8 \\
528 \\
95 \\
1 \cdot 72 \\
38 \cdot 3\end{array}$ & $\begin{array}{l}3 \\
5 \\
1 \cdot 04 \\
181 \\
95 \\
0 \cdot 74 \\
15 \cdot 3\end{array}$ & $\begin{array}{l}4 \\
3 \\
1 \cdot 19 \\
191 \\
100 \\
0 \cdot 89 \\
27 \cdot 6\end{array}$ & $\begin{array}{l}1 / 2 \\
1 \\
1 \cdot 8 \\
283 \\
95 \\
\text { not done } \\
\text { not done }\end{array}$ \\
\hline
\end{tabular}

* Ratio of CSF serum IgG and CSF serum albumin

† Ratio of CSF albumin and serum albumin 
Table 4 Electrophysiological findings in four patients with Bannwarth's syndrome

\begin{tabular}{|c|c|c|c|c|c|}
\hline & Case 1 & Case 2 & Case 3 & Case 4 & Normal $^{*}$ \\
\hline $\begin{array}{l}\text { Facial nerve latency in msec. } \\
\text { Right/left frontalis } \\
\text { Right/left orbicularis oris } \\
\text { Right/left triangularis }\end{array}$ & $\begin{array}{l}5 \cdot 4 / 6 \cdot 4 \\
3 \cdot 8 / 14 \cdot 4 \\
4 \cdot 0 / 17 \cdot 0\end{array}$ & $\begin{array}{l}29 \cdot 0 / 4 \cdot 4 \\
23 \cdot 0 / 4 \cdot 9 \\
19 \cdot 0 / 4 \cdot 0\end{array}$ & $\begin{array}{l}7 \cdot 4 / \text { ne } \\
\text { no resp/ne } \\
\text { no resp/ne }\end{array}$ & $\begin{array}{l}4 \cdot 6 / 4 \cdot 8 \\
4 \cdot 0 / 4 \cdot 4 \\
4 \cdot 1 / 3 \cdot 9\end{array}$ & $\begin{array}{l}3 \cdot 1-5 \cdot 1 \\
2 \cdot 4-4 \cdot 3 \\
2 \cdot 4-4 \cdot 4\end{array}$ \\
\hline $\begin{array}{l}\text { Other nerves } \\
\text { Median nerve (motor and sensory) } \\
\text { Sural nerve } \\
\text { Radial nerve }\end{array}$ & $\begin{array}{l}\text { normal } \\
\text { ne } \\
\text { ne }\end{array}$ & $\begin{array}{l}\text { normal } \\
\text { normal } \\
\text { ne }\end{array}$ & $\begin{array}{l}\text { normal } \\
88 \% \text { reduced amp } \\
\text { of SAP† } \\
\text { normal }\end{array}$ & $\begin{array}{l}\text { normal } \\
25 \% \text { reduced velocity, } \\
\text { normal amp. } \\
\text { ne }\end{array}$ & \\
\hline
\end{tabular}

*normal values related to distance between site of stimulation and recording. $95 \%$ upper and lower limits. ${ }^{8}$

tsensory action potential, ne $=$ not examined

plete nine months later. No steroids were given. The patient had previously been healthy apart from a similar episode of painful dysaesthesiae lasting for a few days the year before. On examination there was a total right-sided peripheral facial palsy including loss of ipsilateral taste and absent stapedius reflex. Light touch elicited painful dysaesthesiae in the T2 dermatome. Shoulder abduction was weak bilaterally. All tendon reflexes and both plantar reflexes were normal. A small eczematous patch was noted under his right nipple. There was no neck stiffness or fever. On the 9th day of hospitalisation the patient developed a partial left-sided peripheral facial palsy. Nine months later there was still a mild right-sided facial palsy. A large number of laboratory tests were normal including ESR, white cell count, serum IgG, IgA, IgM, blood glucose, herpes zoster antibody titre and WR. The CSF was abnormal (see table 3). Microscopy of a biopsy from the affected skin area showed a mild chronic non-specific inflammation. Electromyography was carried out 5 months after the onset of the right facial palsy. There was a reduced recruitment pattern in the right frontalis, orbicularis oris and triangularis muscles and there was evidence of synkinesia. The recruitment pattern in the left frontalis and triangularis muscles was full, but reduced in the left orbicularis oris muscle. Conduction times along the facial nerve to the orbicularis oris, triangularis and frontalis muscles were increased on the right side, but normal or only slightly prolonged on the left (table 4). There was no abnormality in the other nerves studied.

Case 3 A 41-year-old male was admitted to a neurological department with a right-sided facial palsy and weakness of extension of the left arm. Five weeks earlier he had noticed a small red and painful skin lesion on the right side of his abdomen resembling an insect bite. A few days later a reddish ring developed around the lesion, the diameter of which gradually increased to $15 \mathrm{~cm}$. It disappeared after six weeks. One week after the skin lesion appeared he suffered a severe deep burning pain all over his body especially between the shoulder blades. The intensity and the location of the pain varied and was worse at night. Four weeks later he could not extend the fingers on the left side and the following day he developed a right-sided facial palsy. On examination he had a partial right-sided peripheral facial palsy. In the right upper limb there was a moderate weakness of the serratus anterior, biceps and triceps but normal forearm extensors while in the left there was moderate weakness of triceps and a more severe weakness of extensor carpi radialis and extensor digitorum communis. The left brachioradialis muscle was normal as were the tendon reflexes and plantar responses. There were no sensory disturbances, neck stiffness, fever or skin changes. The painful sensation disappeared after 6 weeks and his motor symptoms started to resolve after 6 months. Power was normal after 8 months, apart from minimal weakness of the right serratus anterior and moderate weakness of the left extensor digitorum communis. Eight months later there was still a severe facial weakness with synkinesia. No steroid treatment was given. The initial CSF findings are shown in table 3 and were unchanged 3 weeks later. EMG and nerve conduction studies were performed six weeks after the onset of the facial palsy. Profuse fibrillation potentials without any voluntary activity were found in the orbicularis oris and triangularis muscles on the right side. In the right frontalis muscle there was discrete activity of low amplitude $(300 \mu \mathrm{V})$ on volition and only few fibrillation potentials. The latency to the frontalis muscle was $75 \%$ prolonged. No muscle action potentials could be evoked in the right orbicularis oris or triangularis muscles indicating total denervation of these two muscles. EMG of the left extensor carpi radialis longus muscle showed a reduced recruitment pattern of normal amplitude. EMG of the left extensor digitorum communis muscle revealed discrete activity at maximal effort. At rest there were many sites with fibrillation potentials and positive sharp waves. EMG of the right biceps brachii muscle was normal including a normal mean duration of motor unit potentials and no excess of polyphasic potentials. The conduction velocity along the right sural nerve was normal but the sensory action potential was desynchronised and $88 \%$ reduced in amplitude. The motor and sensory conduction along the right median and left radial nerves was normal (table 4).

Case 4 A 64-year-old female noticed a small, red itchy skin mark on the right forearm, which 2 days later spread to cover her forearm from elbow to wrist. No mark suggesting an insect bite was seen. Eleven days later she felt generally ill with slight fever $\left(38^{\circ} \mathrm{C}\right.$ rectally) and was troubled by severe pain in the back, especially under her left shoulder blade. There was also tenderness of the muscles. Three days later an incomplete left-sided facial palsy developed and she had double vision. On examination the patient was afebrile. She had an incomplete peripheral left-sided facial palsy and a left-sided abducens paresis. Tendon reflexes 
were depressed in the upper and absent in the lower extremities. The plantar responses were flexor and there were no sensory signs. Over the next 10 days she developed a right-sided abducens nerve palsy, a partial right-sided oculomotor nerve paresis and complained of swallowing difficulties. She also developed weakness of her arms and legs so that she could not lift her arms to feed herself or use her fingers, and she could not walk without support. She felt as if she were walking on cushions. Leftsided disc swelling was noted after 4 weeks. All her neurological symptoms and signs disappeared in 2 months. No steroid treatment was given. The patient's past medical history included a mild diabetic mellitus diagnosed 7 years previously, for which she was treated by oral antidiabetics. The CSF findings are shown in table 3. The blood glucose was mildly elevated. Nerve conduction studies and EMG were carried out 15 months after the onset of the disease at a time when she had made a full recovery. They were normal apart from the sural nerve conduction study which showed a $40 \%$ decreased velocity from ankle to mid-calf. The action potential was pathologically split-up but had a normal amplitude. These slight changes could suggest a mild diabetic polyneuropathy.

\section{Discussion}

The symptoms and signs of the four cases presented here are compatible with the so-called Bannwarth's syndrome (that is, lymphocytic meningoradiculitis) where pain followed by weakness, especially of the face are characteristic features. Sensory symptoms often consist of distressing hyperaesthesia. ${ }^{45}$ Of 47 cases collected over 16 years by Hörstrup and Ackermann $^{5}$ nine patients reported a tick bite 3 to 10 weeks before the onset of pain; 15 patients noticed an erythematous patch from a few days up to five and a half weeks prior to the pain phase. Twentynine patients had facial palsies of which 15 were bilateral. All cases occurred between April and October. ${ }^{5}$ Encephalitis or other affections of the central nervous system are unusual in Bannwarth's syndrome. ${ }^{4}$

The most important clinical features of our cases are summarised in table 1 . The skin lesion was a large, round, red and slightly elevated area on the arm, chest or abdomen. One patient had an erythema chronicum migrans. The skin lesion persisted from days to weeks. Their occurrence in June, August and October respectively favour an insect bite followed by a delayed allergic reaction as the cause of the illness. Although no patient could recall a tick bite prior to onset of the disease this does not exclude the possibility of Bannwarth's syndrome. ${ }^{5}$

Deep pain (nerve root pain?) occurred one to three weeks after the onset of the erythema. In three patients the pain was first felt in the back, especially between the shoulder blades, but later all over the whole body changing from one area to another. It continued from 2 to 16 weeks and was especially troublesome at night interfering with sleep. Other sensory symptoms included areas of hypoaesthesia or hyperaesthesia. In case 2 these clearly corresponded to $\mathrm{T} 2$ dermatomes bilaterally.

The first motor symptoms were confined to the facial nerve beginning from between 4 days to 4 weeks after the onset of pain, or $2 \frac{1 / 2}{2}$ to 7 weeks after the erythema. In two patients the facial nerve palsy became bilateral after one week. Other cranial nerves affected were the oculo-motor, the abducens and the glossopharyngeal nerves. Of the peripheral nerves the long thoracic and the axillary nerves were involved as well as $\mathrm{C}_{6}$ and $\mathrm{C}_{7}$ spinal roots.

Routine blood examinations were unremarkable. Serological tests for herpes zoster and Coxsackie A were negative.

All patients had elevated spinal protein concentrations from 1.04-2.8 g/l and a high cell count ranging from 181 to 528 cells $/ \mathrm{mm}^{3}$, mainly lymphocytes (table 3). There was, however, no clinical evidence of meningitis. Similar observations have been made by others. ${ }^{45}$ All patients suffered from headache and tiredness, but none had signs of encephalitis or myelitis. The increased blood brain barrier permeability and the local IgG production within the central nervous system are in accordance with other reports, ${ }^{5}$ as well as in other cases of aseptic meningitis, where the aetiology has been known. ${ }^{9}$ The CSF changes may be long lasting as in our first case ( $3 \frac{1}{2}$ months) (fig).

Although the diagnosis of Bannwarth's syndrome seems most likely in our four cases a number of differential diagnoses have to be considered. Initially the Guillain-Barre syndrome can be dominated by severe back and limb pain and facial diplegia is seen in at least half the cases. ${ }^{10}$ The Guillain-Barré syndrome is regarded as a postinfectious autoimmune demyelinating disorder localised to the peripheral nerves. ${ }^{11}$ The CSF findings in our patients of a high cell count are not compatible with the Guillain-Barre syndrome.

The changes in the spinal fluid, the initial pain and the asymmetrical motor symptoms may resemble acute poliomyelitis. Although polio antibody titres were not estimated in our patients we do not consider this diagnosis likely because of the sensory symptoms, lack of fever and the fact that all patients had been vaccinated against polio. Similarly, infections with other neurotropic viruses such as ECHO and Coxsackie virus are less likely as none of the patients had gastro-intestinal symptoms or pleurodynia. An infection caused by a Coxsackie virus was ruled out in cases 1 and 3 .

The neurotropic effect of the enterovirus, EV 70, has recently been described but none of our cases 
had a preceding acute haemorrhagic conjunctivitis as seen in the epidemics caused by this virus. ${ }^{12}$

In one case shingles was the initial diagnosis because of the severe pain, but this was not supported by serological tests. Neither this case nor any of the others developed the characteristic skin lesions of herpes zoster.

Sarcoidosis with cranial and peripheral nerve involvement may show similar abnormalities of high cell count and elevated protein content in the CSF. ${ }^{13}$ This diagnosis is unlikely as no other signs of sarcoidosis were present. There was no lymph node enlargement and no radiographic chest abnormality.

Meningeal carcinomatosis can present with cranial and peripheral nerve palsies and severe pain..$^{14} 15$ As all our cases improved this diagnosis is unlikely. Cytological examination of the CSF carried out in three cases did not reveal any tumour cells.

Idiopathic facial palsy (Bell's palsy) may be bilateral but is not preceded by skin lesions and severe back pain.

As already mentioned a tick bite, as the cause of the syndrome described, cannot be ruled out. This insect is supposed to cause a number of neurological diseases such as tick paralysis, ${ }^{16}$ erythema chronicum migrans with meningo-radiculoencephalitis, ${ }^{17}$ Bannwarth's syndrome ${ }^{4}$ Lyme disease,,$^{18} 19$ and encephalitis. ${ }^{20}$

Tick paralysis is a fast progressive ascending flaccid paralysis with or without paraesthesias and ataxia caused by a bite from a female tick releasing toxic salivary fluid. ${ }^{1621}$ Pure ataxia without muscle weakness has also been described..$^{22}$ The symptoms usually disappear within hours to days after an engorged tick has been removed. ${ }^{16}{ }^{23}$ The neurotoxic effect is not fully understood, but a botulinum-like effect at the neuromuscular junction has been suggested. ${ }^{16}$

Erythema chronicum migrans is sometimes associated with neurological complaints related to the central and peripheral nervous system. ${ }^{717}$ Many of the earlier reported cases undoubtedly fall into the category of Bannwarth's syndrome. ${ }^{5}$ The erythema in our cases, except for one (case 3), did not fit the classical description of erythema chronicum migrans, in which an expanding ring like erythema with central clearing occurs. Antibodies against tick-borne encephalitis were not tested in our cases. ${ }^{24}$

Lyme disease is a recently described syndrome of erythema chronicum migrans, arthritis and occasionally including neurological symptoms with lymphocytic meningitis. ${ }^{18} 19$ It is believed to be caused by bites of a single species of tick (Ixodes dammini) found more commonly in restricted areas in North America (the Lyme district). ${ }^{25}$ Bannwarth's syn- drome is probably closely related to Lyme disease, but joint pain or joint swelling is not seen in Bannwarth's syndrome.

Finally, it should be stressed that the possibility of rheumatoid arthritis, polyarteritis nodosa or other kinds of arteritis was ruled out because relevant laboratory tests were negative. One patient had a mild diabetes (case 4). We do not believe that this is of any relevance to the present neurological complaints.

\section{ELECTROPHYSIOLOGICAL DATA}

The conduction studies of the facial nerve showed long latencies in two patients, indicating either segmental demyelination or regeneration after Wallerian degeneration. It is likely that both segmental demyelination and Wallerian degeneration with subsequent regeneration occur. In Case 1 , examined only 5 weeks after the onset of the facial palsy the latency along the facial nerve was prolonged about 4-5 times. It is unlikely that Wallerian regeneration had occurred within such a short period of time as the site of the nerve lesions was infrastapedial since the stapedius reflex was preserved but taste was impaired. On the other hand the synkinesias of facial nerve innervated muscles in cases 2 and 3 are probably due to misdirection of regrowing nerve fibres. In case 3, all facial muscles except the frontal were completely denervated, when first examined six weeks after the onset of the disease. In this case there was also weakness of the left extensor digitorum communis and left extensor carpi radialis longus muscles; the latency to the latter muscle was normal and the EMG showed discrete activity indicating partial axonal loss. The radial nerve sensory action potential had a normal shape and amplitude. These findings are compatible with an anterior root lesion of $\mathrm{C}_{7}$ as the brachioradialis muscle was spared.

The clinical and neurophysiological examinations are consistent with anterior and posterior spinal nerve root lesions and cranial nerve lesions. The normal sensory studies in most nerves are in accordance with a lesion central to the spinal ganglion. Except for case 1 EMG changes in facial muscles were compatible with axonal damage. The markedly increased motor latencies along the facial nerve early in the disease could suggest demyelination as a cause of cranial nerve deficiency. In case 2, examined five months after onset of the disease, the prolonged latencies were interpreted as indicating regeneration due to simultaneous findings of synkinesia. Whether demyelination contributed to the conduction delay remains unsettled because nerve stimulation was not performed early in the disease. 


\section{References}

'Bannwarth A. Chronische lymphocytäre Meningitis, entzündliche Polyneuritis und "Rheumatismus". Arch Psychiatr Nervenkr 1941;113:284-376.

${ }^{2}$ Bannwarth A. Die entzündliche Polyneuritis mit dem Liquorsyndrom von Guillain und Barré (polyradiculitis) im Rahmen einer biologischen Krankheitsbetrachtung. Arch Psychiatr Nervenkr 1943;115:566-672.

${ }^{3}$ Bannwarth A. Zur Klinik und Pathogenese der "chronischen lymphocytären Meningitis". Arch Psychiatr Nervenkr 1944;117:161-85; 682-716.

${ }^{4}$ Meyer-Rienecker HJ, Hitzscke B. Lymphocytic meningoradiculitis (Bannwarth's syndrome). In: Vinken PJ, Bruyn GW eds. Handbook of Clinical Neurology. Vol. 34 Amsterdam: North Holland, 1977:571-86.

5 Hörstrup P, Ackermann R. Durch Zecken übertragene Meningopolyneuritis (Garin-Bujadoux, Bannwarth). Fortschr Neurol Psychiatr 1973;41:583-606.

' Dalsgaard-Nielsen T, Kierkegaard A. Allergic meningitis and chronic erythema migrans Afzelii after bite by ixodes reduvius. Acta Allerg 1948;1:388-93.

${ }^{7}$ Pakkenberg H. Meningopolyradiculitis efter skovflåtbid. Nordisk Medicin 1952;48:1007-8.

${ }^{8}$ Trojaborg W. Does cross-innervation occur after facial palsy? J Neurol Neurosurg Psychiatry 1977;40:712-7.

${ }^{9}$ Frydén A, Link H, Norrby E. Cerebrospinal Fluid and Serum Immunoglobulins and Antibody Titers in Mumps Meningitis and Aseptic Meningitis of Other Etiology. Infect Immun 1978;21:852-61.

${ }^{10}$ Arnason BGW. Inflammatory polyradiculoneuropathies. In: Dyck PJ, Thomas PK, Lambert EH, eds. Peripheral Neuropathy. Vol. 2. London: WB Saunders 1975:1110-48.

${ }^{"}$ Abramsky O, Webb C, Teitelbaum D, Arnon R. Cellmediated immunity to neural antigens in idiopathic polyneuritis and myeloradiculitis. Neurology (Minneap) 1975;25:1154-9.

${ }^{12}$ Editorial. Neurovirulence of Enterovirus 70. Lancet
1982;1:373-4.

${ }^{13}$ Delaney P. Neurologic Manifestations in Sarcoidosis. Review of the Literature, with a Report of 23 Cases. Ann Intern Med 1977;87:336-45.

${ }^{14}$ Little JR, Dale AJD, Okazaki H. Meningeal Carcinomatosis. Clinical Manifestations. Arch Neurol 1974;30:138-43.

${ }^{15}$ Olson ME, Chernik NL, Posner JB. Infiltration of the Leptomeninges by Systemic Cancer. A Clinical and Pathologic Study. Arch Neurol 1974;30:122-37.

${ }^{16}$ Pearn J. Neuromuscular Paralysis Caused by Tick Envenomation. J Neurol Sci 1977;34:37-42.

${ }^{17}$ Hellerström S. Erythema Chronicum Migrans Afzelius with Meningitis. Acta Derm Venereol (Stockh) 1951;31:227-34.

${ }^{18}$ Steere AC, Malawista SE, Hardin JA, Ruddy S, Askenase PW, Andiman WA. Erythema Chronicum Migrans and Lyme Arthritis. The Enlarging Clinical Spectrum. Ann Intern Med 1977;86:685-98.

${ }^{19}$ Reik L, Steere AC, Bartenhagen NH, Shope RE, Malawista SE. Neurologic Abnormalities of Lyme Disease. Medicine 1979;58:281-94.

${ }^{20}$ Holmgren B, Lindahl J, Von Zeipel G, Svedmyr A. Tick-borne Meningoencephalomyelitis in Sweden. Acta Med Scand 1959;164:507-22.

${ }^{21}$ Swift TR, Ignacio OJ. Tick paralysis: Electrophysiologic studies. Neurology (Minneap) 1975;25:1130-3.

${ }^{22}$ Gorman RJ, Snead OC. Tick Paralysis in Three Children. The Diversity of Neurologic Presentations. Clin Pediatr 1978;17:249-51.

${ }^{23}$ Morris HH. Tick Paralysis: Electrophysiologic Measurements. South Med Jl 1977;70:121-2.

${ }^{24}$ Granström M, Grandien M, Saikku P. Early Diagnosis of Tick-Borne Encephalitis (TBE) by Demonstration of Specific IgM Antibodies. Scand J Infect Dis 1978;10:97-100.

${ }^{25}$ Steere AC, Malawista SE. Cases of Lyme Disease in the United States: Locations Correlated with Distributions of Ixodes dammini. Ann Intern Med 1979;91:730-3. 